\title{
O QUE EU FUI, O QUE EU SOU... TRABALHO E REMUNERAÇÃO NA VIDA ATUAL DA MULHER IDOSA
}

\author{
Denise Prehn ${ }^{l}$ \\ Flora Bojunga Mattos ${ }^{2}$
}

\section{Resumo}

Esta pesqwisa teve o objetivo de conhecer a influência do fato de ter exercido trabalho remunerado ou não remunerado na forma pela qual as mulheres com mais de 60 anos encaram sua vida atual na velhice. As falas das idosas, com idade variando entre 60 e 80 anos, foram colhidas através de grupos focais com a temática do trabalho. Os dados foram submetidos à Análise de Conteúdo e os resultados sugerem que a aposentaria teve um significado especial para estas mulheres: o grupo que trabalhou fora de casa vislumbrou a perda do espaço social e, ao mesmo tempo concordou com o outro grupo em que só a partir da desobrigação do trabalho exercido no lar, do acontecimento da viuvez e do crescimento dos filhos sentiram-se livres para realizar a si próprias.

Palavras-chave: Mulher; Velhice; Trabalho Remunerado; Trabalho Não Remunerado; Aposentadoria.

\begin{abstract}
The aim of this research was to discover how work, paid or unpaid, influences the way that women over 60 years old deal with their lives in old age. The comments of the old women, aged between 60 and 80 years old, were collected through focus groups, in which the topic was work. The data were examined using Content Analysis and the results suggested that retirement had special significance: while the group that worked out of home discerned the loss of social space, at the same time, it agreed

\footnotetext{
${ }^{1}$ Psicóloga, mestre em Psicologia Social e da Personalidade, doutoranda em Psicologia na Pontifícia Universidade Católica do Rio Grande do Sul, bolsista da CAPES, Porto Alegre RS. E-mail: prenh@zaz.com.br

${ }^{2}$ Psicóloga e psicoterapeuta junguiana no Centro de Psicologia Analítica de Porto Alegre, mestra em Psicologia Social e da Personalidade, Porto Alegre RS. E-mail: florabm@portoweb.com.br
} 
with the other group, in the perception that only with the release from household work, arising from widowhood and the departure of children, did they feel free to fulfill themselves.

Key-words: Woman; Oldness; Paid; Unpaid Work; Retirement.

\section{Introdução}

Partindo do estudo sobre temas que envolvem as mulheres idosas e o trabalho, deparamo-nos com uma questão interessante: o fato de terem exercido uma atividade remunerada ou não remunerada teria influenciado no modo pelo qual estas mulheres vivenciam seu processo de envelhecimento?

Com o propósito de conhecer a resposta a esta questão, que diz respeito à percepção das mulheres idosas sobre si mesmas e sobre o modo pelo qual vivenciam o envelhecimento buscamos distinguir modos de encarar a velhice, tendo como eixo a categoria trabalho.

De antemão, percebemos que as pessoas já na meia idade, por volta dos 50 anos, demonstram interesse em encontrar um novo caminho em suas vidas. Acontecimentos ligados a mudanças biopsicossociais as fazem ingressar em uma nova fase. As mulheres defrontam-se com a menopausa, algumas delas com a aposentadoria, com a saída de casa de seus/suas filhos/as e, muitas vezes, com a morte do marido ou companheiro. Segundo Strey (1989) e Werlang (1989), é através desses acontecimentos que elas se dirigem à etapa seguinte: a velhice.

Nossa pesquisa apoiou-se no critério qualitativo como modelo de construção, análise e interpretação das informações obtidas, o que nos forneceu subsídios para salientar o sentido subjetivo e coletivo de temas ligados ao trabalho e à mulher idosa. Iniciando em uma revisão de literatura, que nos permitiu a contextualização e norteamento da proposta, partimos para a coleta dos dados; os temas emergiram dos grupos e construímos critérios semânticos para a categorização, embasados no problema de pesquisa e objetivos.

Utilizamos como metodologia a abordagem eminentemente qualitativa da Análise de Conteúdo baseada em Bardin (1977). As categorias foram construídas ao longo do processo de análise, fundamentando- 
se em um caminho indutivo-construtivo (MORAES, 1993), que organizou a compreensão dos temas/fenômenos investigados.

A apresentação dos resultados foi organizada do seguinte modo: em primeiro lugar trazendo um breve olhar sobre a velhice da mulher e o trabalho, a seguir mostramos as categorias emergentes nos grupos e o significado que demos a cada uma delas, procurando elucidar as relações sugeridas pelos temas destas categorias.

No presente estudo foram definidas seis categorias, que acreditamos possibilitaram um campo maior de discussão sobre o tema proposto.

\section{Sobre a Velhice}

Conceituar a velhice não é tarefa fácil. Conforme Salgado (1990), há uma informação geral do que é envelhecer, mas não se conhece o suficiente para que exista uma ciência da velhice. A idade de 65 anos tem sido freqüentemente a mais usada para definir o começo da velhice em estudos demográficos e gerontológicos na maioria dos países. No entanto, quando a ONU organizou uma Assembléia Mundial sobre o Envelhecimento, ficou aí estabelecido, que para os países em desenvolvimento a velhice começaria a partir dos 60 anos, devido às dificuldades sócio-econômicas vividas pelos mesmos (CORRÊA, 1996).

Muito embora se considere uma pessoa de 60 ou 65 anos no início da velhice, na maioria das vezes é difícil assegurar quando esta começa realmente, já que se deve levar em conta as diferenças individuais, físicas e psicológicas, assim como as variáveis do contexto social em que está inserida (CORRÊA, 1996; BALLESTEROS; FERRER, 1994). Para estes/as autores/as, o envelhecimento abarca, ainda, o processo biológico, o fenômeno social e uma realidade subjetiva e comportamental. Por outro lado, temos uma proliferação de etapas no processo de envelhecimento. Enfim, caracterizar a velhice requer a descrição de uma diversidade de aspectos.

Para Prada (1996), a descrição dessa diversidade é o mais importante, pois ao envelhecer, menos semelhantes e mais diferenciadas ficam as dimensões de vida de uma pessoa. Algumas sentem o envelhecimento como um processo de enriquecimento da vida interior, enquanto 
outras vivem essa fase com grande sofrimento, com perdas importantes que levam a doenças, solidão e isolamento (CORRÊA, 1996).

A psicologia junguiana prestou muita atenção às etapas avançadas da vida. Pautado nas observações de seus pacientes, Jung (1984) acentuou que as pessoas ao envelhecer necessitam conseguir se dedicar muito mais ao seu próprio si mesmo. Ele costumava fazer uma analogia do percurso de vida com o caminho do sol diariamente. Dizia que a velhice assemelhava-se ao poente: o sol, depois de ter esbanjado luz e calor sobre o mundo, recolhe os seus raios para se iluminar a si mesmo. Ele enfatizava a diferença entre as pessoas que chegavam à velhice com aspirações e desejos irrealizados e as que tivessem vivido o máximo de si. As primeiras desviavam o olhar para trás, para o passado, lamentando-se do que lá ficou e não poderia mais ser vivido, enquanto as outras abençoariam a quietude da velhice, que neste momento seria bem-vinda, empreendendo o recolhimento sobre si próprias. O trabalho mais importante a ser feito com as pessoas, neste caso, seria proporcionar a elas se darem conta do seu momento de vida, possuindo sempre um objetivo fixado no futuro, o que é importante em todas as fases da vida, mas, principalmente, o é na velhice.

\section{A Velhice da Mulher na nossa Sociedade}

Atualmente a maioria das mulheres brasileiras idosas, ao chegar à velhice, demonstra sentir-se mais à vontade em casa do que os idosos, já que, ao contrário destes, grande parte delas exerceu seus trabalhos mais em casa do que fora. Muitas não se ocuparam com o trabalho fora do lar e não tiveram sequer uma instrução formal. Grande parte era, e continua sendo, dona de casa (CCDH, 1997), engrossando o índice de analfabetismo, que chega em nosso país a $48 \%$ das mulheres com mais de 65 anos.

Para Peixoto (1997), esse índice enorme de analfabetismo entre as mulheres idosas deveu-se ao fato de nascerem por volta de 1920 e 1930, quando tinham pouco acesso à escolarização. Além disso, a mulher dessa geração era educada apenas para o casamento e preparada para só se envolver com a casa, com o marido e com o cuidado da prole, sendo desestimulado o estudo assim como o trabalho fora de casa. 
Segundo Debert (1999), o fato de a maioria das mulheres idosas não ter tido uma vida profissional ativa e de terem vivenciado uma forte repressão sexual faz com que elas na velhice, falassem em seus relatos de seu sofrimento, de sua solidão, o que de fato seria resultado da situação do feminino na nossa sociedade como um todo. Com isso haveria uma cota de perdas colocada na velhice que se atribuiria à mulher da sua época, e que acreditariam poder recuperar se fossem jovens. Apesar disso, salienta a autora, elas não se sentem tão vítimas como a maioria das teorias as coloca, já que em relação às suas mães e avós, são consideradas privilegiadas. Considerando a experiência atual da velhice, elas estão mais liberadas das obrigações a que se submeteram quando jovens. Agora são livres para a realização de atividades prazerosas, já que o contexto cultural está cada vez mais receptivo com as mulheres mais velhas. Por sua vez, as marcas etárias estão cada vez mais apagadas: podemos encontrar mães e avós na mesma faixa etária, já que os progressos na área da reprodução humana e o ingresso maciço das mulheres no mercado de trabalho possibilitam que elas sejam mães pela primeira vez tanto aos dezesseis anos como aos quarenta e cinco. A história estaria escrevendo uma sociedade em que a idade cronológica torna-se irrelevante e o estilo de vida é o que vale para marcar a diferença. As fronteiras começam a se construir de outro modo e nossas idosas estariam participando desse processo de transformação.

Mesmo hoje, as mulheres idosas aposentadas de uma atividade profissional não manifestam, significativamente, o sentimento de desqualificação, que tanto incomoda os homens idosos. Elas conseguem se envolver mais facilmente com as tarefas dentro de casa ou participar de atividades junto a outras pessoas seja em clubes, igrejas, universidades para a terceira idade, etc. Em todos os âmbitos a aposentadoria ativa se contrapõe à aposentadoria no sentido de recolhimento, muito mais entre as mulheres do que entre os homens. Elas assumem o movimento gerado pela terceira idade, mais intensamente. Sabemos que esse movimento tem mobilizado um público feminino que ultrapassa $80 \%$ a participação masculina (DEBERT, 1999).

A conquista da liberdade feminina veio redefinir o envelhecimento das mulheres, mesmo para as que já estão vivenciando esse processo de velhice. Junto com o tema da terceira idade criaram-se novas regras 
e estilos de vida. Para Debert (1999), tornou-se possível envelhecer escapando aos padrões ditados pelas sociedades antigas, os quais eram mais rígidos para com as mulheres.

As idosas pensam e comparam sua vida atual com as mulheres velhas de antigamente e dizem que aconteceram muitas mudanças, uma delas é que antes as viúvas precisavam trabalhar, fazendo pães, doces, etc. para se sustentar e criar os/as filhos/as, já que não recebiam pensão ou aposentadoria. Hoje as idosas procuram tirar o máximo proveito, tanto da pensão, quanto dos recursos que possuem. Muitas delas não querem se preocupar em deixar herança. Acreditam que devem viajar, confraternizar com as amigas, enfim, usufruir a vida como é apregoado pelo movimento gerado pela terceira idade (MATTOS; TRUCCOLO; MEDEIROS; SILVA; MELLO, 1998).

\section{Sobre o Trabalho}

Foi a partir do processo de industrialização que se estabeleceu a divisão do trabalho no campo social entre o público e o privado, atribuindo-se ao primeiro as características de produtividade e remuneração, enquanto que ao segundo coube a afirmação de sua condição de não produtivo e, por consequiência, o fato de ser não remunerado.

O trabalho produtivo, realizado até então nas unidades familiares, transferiu-se para o espaço público das fábricas, o que limitou a participação das mulheres a quem coube o cuidado com os filhos e com as tarefas da casa, ficando, desse modo, limitadas ao espaço privado. (MARTINEZ; MOYA; MUÑOZ, 1995). Essa fragmentação do trabalho resultou que aos homens coube o trabalho produtivo, pelo qual se recebe um salário, e às mulheres coube o trabalho doméstico, não havendo por ele uma remuneração.

Como conseqüência dessa situação, e lembrando que dentro do sistema econômico capitalista os ganhos financeiros são determinantes para a inserção social de quem os aufere, exercer uma atividade não remunerada era ter seu trabalho invisibilizado e sua voz calada, até mesmo como cidadãs. O tipo de trabalho exercido passa, a partir da revolução industrial, a definir o que alguém é (PREHN, 1999). 
Não é nosso interesse retomar a discussão sobre o valor econômico do trabalho doméstico não remunerado, e nem mesmo arriscarmonos na discussão sobre identidades mas, isso sim, afirmar o quanto é determinante em termos sociais para quem o exerce e tem sua significação subjetiva definida através dele (CARLOS; JACQUES; LARRATÉA; HEREDIA, 1999).

Na segunda metade do séc. XX, em virtude de uma série de fatores, mais e mais mulheres entraram no espaço público, trabalhando nas mais diversas atividades e recebendo uma remuneração (ainda que inferior a dos colegas homens). Da mesma forma, elas conquistaram o direito à aposentadoria.

Ao contrário dos homens, entretanto, para as mulheres, a aposentadoria não significa o fim do trabalho, pois ao se retirarem do espaço público, elas seguem realizando tarefas no espaço privado, do qual nunca chegaram a se afastar. Podemos apontar isto, que se consagrou chamar dupla jornada de trabalho, como um diferencial entre a situação de aposentadoria para homens e mulheres, uma vez que o trabalho atribuído às mulheres parece não ter fim.

Assim, diante dessa realidade social tão fortemente influenciada pelo trabalho e pelos ganhos financeiros, surgiu mais uma diferenciação: mulheres que exerceram atividades remuneradas e as que não recebem remuneração pelo seu trabalho, conferindo à aposentadoria significados diferentes em cada um dos casos.

\section{As Categorias Pesquisadas}

Antes de passarmos ao material analisado se faz necessário falar um pouco sobre as mulheres que construíram, através de suas falas, esta pesquisa.

Participaram desta pesquisa onze mulheres com idade variando entre 60 anos e 80 anos, viúvas que moram sozinhas ou com um/a dos/ as seus/suas filhos/as em um bairro de classe média de Porto Alegre. As cinco que exerceram profissões fora de casa trabalharam em diferentes setores do serviço público, ocupando-se de atividades consideradas femininas, tais como secretaria e professora. Do total, seis freqüentam grupos de convivência da terceira idade, quatro não participam de ne- 
nhum grupo e uma faz parte de um grupo de mulheres em uma igreja. A escolha das participantes foi aleatória, devendo-se a sua disponibilidade de deslocamento até o local onde aconteceram os encontros. Divididas em dois grupos, falaram sobre sua percepção a respeito do trabalho que realizaram em suas vidas durante aproximadamente uma hora.

A escolha da técnica de grupos focais deveu-se ao privilégio da dimensão social que permite, assim como ao grande volume de informações que fornece, salientando o sentido subjetivo e coletivo de temas ligados ao trabalho e à mulher da terceira idade. (GUARESCHI ${ }^{3}$; ROSO, 1997).

Trazemos, a seguir, alguns exemplos das falas que constituem as categorias utilizadas neste estudo. Essas categorias emergiram dos temas trazidos por elas e foram agrupadas segundo sua afinidade.

A categoria trabalho remunerado $o^{4}$ referiu-se ao trabalho profissional que as mulheres exerceram e pelo qual receberam remuneração regular. As mulheres que se ocuparam desta atividade referiram-se a ela com satisfação: "amei a minha vida de profissional""; "adorava trabalhar fora"; "gostava de trabalhar na repartição". O casamento apareceu como um corte na possibilidade do exercício profissional, porque significou assumir as responsabilidades do cuidado de filhos/as e da casa, o que inviabilizou o exercício profissional para muitas delas: "eu trabalhei quando solteira, depois... eu casei”. O trabalho foi apontado como um elemento fundamental para a vida: "meu trabalho foi a minha sobrevivência", enquanto o fim do trabalho profissional, devido à idade, mostrou-se como fator de exclusão social: "eu trabalhei muitos e muitos anos, mas ninguém quer mais uma pessoa de 67 anos", revelando que nem sempre a aposentadoria é uma opção, tornando-se mais uma imposição social.

A categoria trabalho não remunerado aplicou-se ao trabalho que não envolveu qualquer tipo de remuneração direta por ele. Era um trabalho sem valor definido. Elas expressaram suas percepções sobre como

\footnotetext{
${ }^{3}$ Informação verbal recebida durante as aulas do curso de Pós-Graduação em Psicologia na PUCRS, 1996.

${ }^{4}$ As palavras e expressões em itálico referem-se às categorias daqui por diante.

${ }^{5}$ As palavras e textos colocados entre aspas e em negrito indicam a fala ou a transcrição literal retirada dos grupos.
} 
sentiam a des/valorização dessas tarefas: "dizem que a dona de casa não faz nada"; "acho que o trabalho da dona de casa é um trabalho ingrato"; "nem o marido reconhece, nem os filhos, acaba ficando uma escrava da casa"; "é um trabalho escravo"; "trabalho cansativo que não aparece nunca"; "é todo o dia a mesma coisa"; "eles não vêem a gente fazer". Estas falas permitem identificar a presença de um discurso crítico sobre as atividades domésticas e sobre a apropriação de seu tempo pela família.

O conteúdo presente nas falas, sobre o trabalho em casa, variou entre gostar e ter prazer, quando se referiam ao momento presente: "eu gosto de limpar"; "eu gosto é de arrumar, de limpar a minha casa, eu adoro"; "eu nasci para ser dona de casa"; e não gostar e não assumir: "como dona de casa sou uma negação"; "como dona de casa eu sou mediana"; "eu nunca trabalhei". Ao mesmo tempo, o fato de assumir e aceitar este trabalho como um destino: "minha mãe me preparou para ser dona de casa". Ressaltamos o sentimento de liberação da obrigação de realizar este trabalho, trazendo em si o significado do fim da disponibilidade em tempo integral: "eu trabalhei muito em casa, agora não faço nada e não quero fazer"; "a minha cota está cumprida"; "trabalhei a vida inteira, agora sou moleque de rua"; "dentro de casa trabalhei muito". Destas descrições emergiram a ambivalência entre os sentimentos de orgulho, pela própria capacidade de trabalho, ao mesmo tempo em que se conserva uma posição servil: "eu criei cinco sem babá"; "faço toda a minha lida da casa"; "acho que trabalho a gente não deve nunca parar"; "eu acho que a gente tem que servir, mas não toda a vida"; "eu tô aí prá uma doença, prá uma necessidade".

$\mathrm{Na}$ categoria aposentadoria apresentaram-se duas definições, de acordo com o tipo de atividade exercida: na atividade remunerada é utilizado o critério legal; na atividade não remunerada, a aposentadoria foi vista como o momento a partir do qual essas mulheres consideraram que cessou sua obrigação de trabalhar, isto é, o compromisso com a realização do trabalho em casa e com a família: "eu me aposentei. Não de trabalho. Eu me aposentei de convivência com neto, de convivência com filho"; "sou muito de trabalho mas também agora dei uma parada"; "porque antes eu tinha marido, trabalhava mais então"; "não tenho mais tanta preocupação"; "tô mesmo aposentada mesmo, apo- 
sentada em tudo". A partir de então começou uma outra etapa na qual é possível explorar novas possibilidades: "ainda quero ser útil"; "a gente tem o direito de viver a minha vida"; "bastante ativa e eu não quero ficar parada".

A categoria como se percebe referiu-se ao conceito que elas tinham de si. Algumas não se reconheciam na velhice : "na minha cabeça eu tenho 17 anos, então não me olho no espelho"; "roupa de velha eu não gosto". Ao contrário, outras aceitavam e se reconheciam idosas: "eu aceito as minhas limitações"; "eu não me garanto se funciono mais"; "quando começa dor aqui, dor ali, se eu não tivesse velha não teria tanta dor"; "eu acho que porque eu sou velha, tenho 73 anos, eu gosto de fazer aquilo" (referindo-se a arrumar a casa). Por outro lado, surgiram os projetos para essa etapa atual de vida: "eu quero fazer algo prá mim, algo que goste"; e a nostalgia da juventude: "eu adoro estar no meio de gente jovem, até o sofrimento deles é bonito".

A categoria necessidade de atualização realçou a preocupação dessas mulheres de manterem os vínculos sociais e familiares: "nós temos que conviver com isso, com essa nova geração"; "eu tenho que aprender a conviver com esses modernismos todos", "então tem que fazer uma atividade, eu gosto muito de fazer curso". Através desta atualização acontecia a manutenção do seu papel dentro da família: "aí eu tenho assunto com eles. Eu tenho que entrar na deles"; "a gente aprende todos os dias".

Algumas das falas que referimos à necessidade de atualização permitem vislumbrar o sentimento de incerteza, quanto a sua própria capacidade do desafio: "aprender a conviver com esses modernismos sem se revoltar"; "mas eu gostaria de mudar, de estudar, mas a minha cabeça não dá mais.

$\mathrm{Na}$ categoria incertezas foram expressos os sentimentos e os temores em relação ao futuro: "não tenho idéia de como vai ser o meu futuro"; "meu futuro? O que me espera?"; "eu prefiro nem pensar nele"; "eu tenho confiança que acho que os filhos vão me cuidar"; "por alguma razão isso (ir para um asilo) pode acontecer". 


\section{Discussão}

O trabalho em atividades dentro da chamada "unidade de produção" (LOPES, 1997) permitiu a algumas dessas mulheres visibilizaremse socialmente, a partir do reconhecimento obtido através da remuneração e de sua entrada no espaço público. Isto fica evidenciado na categoria trabalho remunerado, na qual foram feitas claras as referências ao sentimento de satisfação originadas do exercício de atividades reconhecidas no seu meio social. Mesmo que não fossem responsáveis pelo sustento familiar, o fato de possuírem uma renda própria e de estarem inseridas no mundo do trabalho formal lhes conferia uma posição de destaque na sua família e na sua comunidade. Entretanto cabe lembrar que, mesmo tendo exercido uma atividade profissional específica, nunca lhes foi permitido abandonar a preocupação com o funcionamento da estrutura doméstica, sendo essa de sua total responsabilidade: ou executavam as tarefas domésticas pessoalmente ou administravam o trabalho de empregados/as da casa. Mesmo atualmente, quando falam dessa sobrecarga de tarefas revelam a aceitação da 'naturalização' da atividade doméstica, como sendo de responsabilidade das mulheres, o que não chega a nos causar surpresa em se tratando de uma geração na qual muitas das conquistas feministas apenas se delineavam na sociedade ocidental.

Na categoria trabalho não remunerado, notadamente, as manifestações revelaram o sentimento de desvalorização, que se originou, principalmente, no fato do serviço doméstico não receber reconhecimento, nem das próprias mulheres. Isto ficou claro na expressão "eu nunca trabalhei", utilizada para definir sua condição de dona de casa, que coloca o trabalho doméstico como um não-trabalho mesmo que dele se ocupassem ininterruptamente durante anos a fio. As manifestações que compõe esta categoria indicaram-nos que as atividades domésticas realizadas pela mulher foram frutos da maneira pela qual ela foi socializada, estando mais ligadas a essa socialização do que à realização ou desejo pessoal.

Observamos que cessada a obrigatoriedade de realizar as tarefas no lar, as mulheres manifestaram o desejo de se envolverem com outros tipos de atividades até então adiados. O término do sentimento de 
obrigatoriedade, abrindo a oportunidade de buscar a realização pessoal, foi relacionado à categoria aposentadoria, e é interessante salientar que, mesmo as novas atividades com as quais se ocupam não são remuneradas, evidenciando mais a necessidade de ocupar o tempo do que a preocupação com o seu papel social. Poucas são aquelas que saem em busca de um desafio maior por considerarem que sua vez já passou.

A categoria aposentadoria revelou-nos também uma outra conotação, a qual diz respeito às relações afetivo-familiares, principalmente no que se refere às mulheres que exerceram trabalho não remunerado. Dos grupos emergiu o sentimento de liberação diante da responsabilidade de cuidar da família, de ocupar o papel de cuidadora e das cobranças familiares para que assumissem essa função, e que pode ser exemplificada pela expressão "eu me aposentei. Não de trabalho. Eu me aposentei de convivência com neto, de convivência com filho" manifestada no grupo.

Não podemos deixar de citar, entretanto, a sensação de desânimo apontada por algumas delas que não se sentem interessadas por atividades alternativas e parecem apontar para uma confusão entre aposentadoria e inatividade. Para estas, longe de significar a possibilidade de se reinventar, a aposentadoria apresenta-se como a proximidade do fim de suas possibilidades como pessoa.

A categoria necessidade de atualização apareceu como uma preocupação não só de manter e renovar os vínculos familiares existentes, mas também de estabelecer relações com as novas gerações, restabelecendo a inserção social. Poderíamos dizer que esta é uma categoria típica da contemporaneidade, na qual todas as pessoas estão sobre o impacto da atualização constante e sob o temor da obsoletização. Esta categoria apresentou um forte sentimento de necessidade: "tem que fazer..."; "eu tenho de aprender..."; "nós temos que conviver..."; etc.; de certa forma, como se não houvesse outra opção. Curiosamente, foi através da necessidade de atualização que percebemos indícios da imagem que elas tinham de si mesmas, pois apareceram manifestações de insegurança quanto à própria capacidade de aprender. Neste ponto a categoria como se percebe nos auxilia ao mostra as oscilações que acontecem entre a consciência das limitações que sentem e a negação destas limitações, evidenciando-se as dificuldades em enfrentar as mudanças físicas e sociais decorrentes da velhi- 
ce, situação que não podem evitar e que nem sempre aceitam com tranqüilidade. A manifestação de depressão ("dor aqui e dor ali”), negação (não me olho no espelho") e inveja da juventude ("até o sofrimento deles é bonito"), revelaram seus sentimentos de perda, o que não nos surpreende, uma vez que há uma mensagem social largamente reafirmada, através da mídia, que nos diz ser permitido envelhecer, mas absolutamente inadequado parecermos velhos/as.

A categoria incertezas apresentou-se quase como uma conseqüência da categoria anterior, reforçando o sentimento de insegurança quanto aos vínculos familiares e ao próprio papel social. De fato, o que se constatou foi uma atitude de evitação relacionada com o pensar no futuro, muitas vezes, revelando o temor de se tornar um incômodo para a família e ter de enfrentar a situação de abandono em um asilo.

Neste ponto cabe observarmos que, para quem exerceu uma atividade profissional remunerada, a aposentadoria ao mesmo tempo em que significou o descanso merecido, após seu período de contribuição social e a possibilidade de se envolver com novas atividades, também representou a perda de uma experiência satisfatória, de um espaço conquistado, no qual foi obtido o reconhecimento social desejado. Isto ficou claro nas referências explícitas ao gosto pela atividade profissional, tais como "amei minha vida de profissional", "adorava trabalhar fora", "eu gostava de trabalhar na repartição".

Em contrapartida, para quem se dedicou ao exercício de uma atividade não remunerada, como o cuidado com a casa e a família, a 'aposentadoria' teve a conotação de um sentido não legal. Soou como a libertação de uma obrigação ("minha cota eu já cumpri”) e a possibilidade de, finalmente, ter tempo para si própria.

Foi interessante observar a ausência de manifestações de prazer no trabalho com a casa e a família, demonstrando mais satisfação com tarefas específicas, como o cuidado da casa, o qual realizam atualmente sem compromisso. Foi fácil compreender este sentimento, uma vez que esse tipo de atividade foi descrita como cansativa, contínua, rotineira, limitante e limitada. Além disso, podemos observar que, para a maioria dessas mulheres, não houve a possibilidade de escolha, e assumir as responsabilidades domésticas foi cumprir um papel já predeterminado ("minha mãe me preparou para ser dona de casa"). De modo geral, o 
trabalho doméstico da mulher iniciou quando ela foi estimulada a aprender e executar pequenas tarefas dentro de casa, normalmente auxiliando outras mulheres, em troca de assinalar seu espaço dentro da estrutura familiar.

Outro grande ausente é o dinheiro, totalmente esquecido nas suas manifestações. As referências ao exercício de uma atividade remunerada trouxeram consigo o valor social percebendo-se o dinheiro como um elemento secundário para elas. De certo modo, é esperado, pois o dinheiro era, até recentemente, vinculado a um materialismo historicamente dissociado da figura feminina, não sendo utilizado para fazer referência a mulheres.

\section{Conclusões e Reflexões}

Ao iniciar esta pesquisa pensávamos que o exercício de uma atividade profissional remunerada, ou não, pudesse ser um fator importante na auto-percepção de mulheres de mais de 60 anos.

Descobrimos que é realmente importante mas não determinante, já que a maioria delas não teve a opção de questionar sua atividade, permanecendo no espaço doméstico que consideravam natural. Envolver-se com as atividades da casa não lhes deu satisfação, mas isso não chega a ser percebido como um problema, pois não havia essa expectativa uma vez que estavam repetindo o trabalho das mulheres da família como quem aceita um destino.

Aquelas que se dedicaram a atividades no âmbito público viveram contextos diferentes, pertencendo a associações de classe e assemelhados, e conquistando tanto o reconhecimento do valor de seu trabalho através de uma remuneração quanto uma identidade social definida que as acompanha mesmo após a aposentadoria, entretanto mesmo elas estavam vinculadas ao cuidado com a casa, acumulando as funções de profissional, mãe, esposa e administradora doméstica.

Ao contrário do que imaginávamos, em relação à independência e à autonomia, o que pudemos observar é que tanto as mulheres que exerceram atividade remunerada quanto as que não receberam remuneração, tendiam a agir da mesma forma na administração de sua vida atual e de seus proventos. A diferença entre elas apareceu mais claramente relaci- 
onada à situação de viuvez do que propriamente à atividade exercida, uma vez que foi só a partir deste momento que as mulheres do grupo não remunerado começaram a administrar suas finanças sozinhas.

A nós parece que a diferença mais importante entre os dois grupos de mulheres é a forma pela qual cada um atribuiu um significado à aposentadoria e à maneira utilizada para dar sentido ao ficar em casa; enquanto para um grupo a aposentadoria significou a perda do espaço social, para o outro trouxe a liberação de uma atividade desvalorizada socialmente e desprovida de possibilidades de realização pessoal.

A aposentadoria teve um significado singular para essas mulheres, pois associaram-na às relações afetivo-familiares, ou seja, à liberação da responsabilidade do cuidado com a família, da obrigatoriedade de realizar as tarefas domésticas, principalmente para a viúva que mora só. Notamos que esta, especialmente, quer aproveitar esta liberdade para realizar a si mesma pois este é o momento em que, pela primeira vez na vida, pode tomar suas próprias decisões.

Tendo conversado com mulheres que são ainda frutos da sociedade ocidental anterior à eclosão do movimento feminista e que, por isso mesmo, ocupavam um espaço social limitado e limitante em suas possibilidades de questionamento e ação, encontramos resultados coerentes com essa realidade. Cabe a nós, entretanto, refletirmos quanto a algumas questões que inevitavelmente se colocam à partir destes resultados.

A sociedade brasileira ainda não está preparada para lidar com seus velhos dentro da nova realidade de maior longevidade e melhor qualidade de vida, e ainda associa a aposentadoria como o final da vida, vendo-os como alguém que já encerrou sua participação social. Lentamente surgem algumas iniciativas profissionais para pessoas com mais de 60 anos, mas são casos ainda raros. A existência de espaços dentro da Universidade pode criar novos caminhos para essa parte da população, mas seu acesso é limitado.

Em breve começaremos a ter mulheres que já vivem as idéias feministas entrando nessa faixa etária. São mulheres decididas, que enfrentaram muitos desafios para defenderem suas posições e que fizeram suas escolhas. De que maneira nossa sociedade poderá dar conta das expectativas dessas mulheres que certamente não mais aceitarão esse 
lugar de exclusão social? Que significados atribuirão à aposentadoria, ao trabalho e às relações sociais?

Muitas outras questões surgem e surgirão nos próximos anos envolvendo o envelhecer e o contexto psicossocial em que vivemos. Cabe a nós prosseguir pesquisando para revelar as respostas.

\section{Referências}

1 BALLESTEROS, R. F.; FERRER, A. R. Evaluación conductual en la vejez. In: BALLESTEROS, R. (Org.). Evaluación conductual hoy - un enfoque para el cambio en psicología clínica y la salud. Madrid: Pirámide, 1994. p. 743782.

2 BARDIN, L. Análise de Conteúdo. Lisboa: Edições 70, 1977.

3 CARLOS, S. A.; JACQUES, M. G.; LARRATÉA, S.; HEREDIA, O. Identidade, Aposentadoria e Terceira Idade. Estudos Interdisciplinares sobre o Envelhecimento, Porto Alegre, v. 1, p. 77-88, 1999.

4 CORRÊA, A. C. de O. Envelhecimento, Depressão e Doença de Alzheimer. Belo Horizonte: Health, 1996.

5 DEBERT, G. G. A Reinvenção da Velhice: socialização e processos de reprivatização do envelhecimento. São Paulo: Editora da Universidade de São Paulo; Fapesp, 1999.

6 JUNG, C. G. As etapas da vida. In: Idem. Obras Completas. Petrópolis: Vozes, 1984. v. VIII/2, cap. XVI, p. 335-353.

7 LOPES, M. J. M. Mulheres, Saúde e Trabalho. In: STREY, M. N. (Org.). Mulheres, Estudo de Gênero. São Leopoldo: UNISINOS, 1997. p. 107-113.

8 MARTÍNEZ, A.; MOYA, J.; MUÑOZ, M. Mujeres, espacio y sociedad: hacia una geografía del género. Madrid: Síntesis, 1995.

9 MATTOS, F. B.; TRUCCOLO, A.; MEDEIROS, P. F. de; SILVA, C. E.; MELLO, D. C. de. Gênero e as Percepções das Pessoas na Terceira Idade. Psico, Porto Alegre, v. 29, n. 2, p. 83-106, jul./dez. 1998.

10 MORAES, R. Análise de Conteúdo. Educação, Porto Alegre, v. 22, n. 37, p. 7-31, 1993.

11 PEIXOTO, C. De Volta às Aulas ou de Como Ser Estudante aos 60 Anos. In: VERAS, R. (Org.). Terceira Idade - desafios para o terceiro milênio. Rio de Janeiro: Relume-Dumará; UnATI/UERJ, 1997. p. 41-74.

12 PRADA, C. Um País que Amadurece. Problemas Brasileiros, São Paulo, v. 315, p. 4-9, 1996. 
13 PREHN, D. Divisão Sexual do Trabalho: isso é coisa de mulher? In: STREY, M.; ROSO, A.; MATTOS, F.; WERBA, G. (Org.). Gênero por Escrito. Porto Alegre: EDIPUCRS, 1999.

14 RIO GRANDE DO SUL. Assembléia Legislativa. Comissão de Cidadania e Direitos Humanos (CCDH). Cidadania na Terceira Idade. In: Relatório Azul 1996. Porto Alegre, 1997. p. 73-86.

15 ROSO, A. Grupos Focais em Psicologia Social: da teoria à prática. Psico, Porto Alegre, v. 28, n. 2, p.155-169, 1997.

16 SALGADO, C. D. S. Trabajo social y vejez - teoría e intervención. Buenos Aires: Humanitas, 1990.

17 STREY, M. N. A Mulher e a Aposentadoria: uma crise passageira ou a contabilização de mais uma perda? Psico, Porto Alegre, v. 18, n. 2, p. 75-89, 1989.

18 WERLANG, B. S. G. Velhice Feminina e Sexualidade. Psico, Porto Alegre, v. 17, n. 1, p. 91-100, 1989. 